\title{
Fairness from the Top: Perceived Procedural Justice and Collaborative Problem Solving in New Product Development
}

John B. Bingham

jbbingham@gmail.com

Haiyang Li

Elizabeth E. Umphress

Follow this and additional works at: https://scholarsarchive.byu.edu/facpub

Part of the Business Administration, Management, and Operations Commons

\section{Original Publication Citation}

Li, H., Bingham, J. B., \& Umphress, E. E. (27). "Fairness from the top: Perceived procedural justice and collaborative problem solving in new product development". Organization Science, $18,2-216$.

\section{BYU ScholarsArchive Citation}

Bingham, John B.; Li, Haiyang; and Umphress, Elizabeth E., "Fairness from the Top: Perceived Procedural Justice and Collaborative Problem Solving in New Product Development" (2007). Faculty Publications. 953.

https://scholarsarchive.byu.edu/facpub/953

This Peer-Reviewed Article is brought to you for free and open access by BYU ScholarsArchive. It has been accepted for inclusion in Faculty Publications by an authorized administrator of BYU ScholarsArchive. For more information, please contact ellen_amatangelo@byu.edu. 


\title{
Fairness from the Top: Perceived Procedural Justice and Collaborative Problem Solving in New Product Development
}

\author{
Haiyang Li \\ Jesse H. Jones Graduate School of Management, Rice University, Houston, Texas 77005, haiyang@rice.edu \\ John B. Bingham \\ Department of Organizational Leadership and Strategy, Marriott School of Management, \\ Brigham Young University, Provo, Utah 84602, johnbingham@byu.edu \\ Elizabeth E. Umphress \\ Department of Management, Mays Business School, Texas A\&M University, \\ College Station, Texas 77843-4221, eumphress@cgsb.tamu.edu
}

\begin{abstract}
$T^{\mathrm{s}}$ The literature on new product development has examined several important determinants of collaboration among project members. However, we are not aware of any study that links top management decisions with project members' collaborative behavior. To address this significant gap, this study examines how perceived procedural justice in top management decisions regarding new products is related to collaborative problem solving among new product development project members. Our results from 109 technology firms - as well as from 91 student-based project groups-suggest that perceived procedural justice in top management decisions is positively related to collaborative problem solving among project members, and that collaborative problem solving mediates the relationship between perceived procedural justice and new product performance. Furthermore, we found that the relationship between perceived procedural justice and collaborative problem solving is positively moderated by environmental uncertainty. Contrary to our expectation, however, our findings show a negative moderating effect of project members' perceived organizational commitment on the relationship between perceived procedural justice and collaborative problem solving.
\end{abstract}

Key words: perceived procedural justice; new product development; collaborative problem solving

Product innovation is a critical determinant of organizational performance and survival because it is the means by which organizations develop new markets and technologies, as well as adapt and transform themselves in changing environments (Brown and Eisenhardt 1995, Smith et al. 2005). Demonstrating the critical importance of product innovation, previous work indicates that new products account for one-quarter to one-third of firms' financial growth (Booz, Allen, and Hamilton 1982; Zirger and Maidique 1990).

Successful new product development requires extensive collaboration among project group members, such as jointly developing agendas, intensely exchanging information, and collaboratively solving product-related problems (Brown and Eisenhardt 1995, Song et al. 1997). Such collaboration requirements are particularly important in technology industries, where dynamic market changes require project members to be highly interdependent to reduce the uncertainty in product development processes and to increase development speed (Atuahene-Gima and Li 2004, Brown and Eisenhardt 1995). As Sutton and Hargadon (1996, p. 703) observed, “... no person can consistently design good products alone; the process requires knowledge about too many things and making many trade-offs between constraints."
Previous studies have examined several important determinants of collaboration among project members, such as members' demographic characteristics, information utility, and reward structures (e.g., Ancona and Caldwell 1992). However, we are not aware of any study that examines how top management decisions regarding new product development may relate to project members' collaborative behavior. This is a significant gap because top management plays a critical role in product innovation, and prior research has shown that the support and commitment of top management are related to new product success (Swink 2000, Zirger and Maidique 1990). Thus, linking top management product decisions with project members' collaborative behavior can help us better understand the role of top management in product innovation. In particular, we may gain insights into how top management decisions are related to new product performance through their effect on collaboration among project members. In this paper, we address this gap by drawing from the procedural justice literature.

Research on procedural justice suggests that the perceived fairness of organizational procedures may affect individuals' reactions to the outcomes they receive, as well as their evaluations of the parties responsible for the decisions (Thibaut and Walker 1975). Fairness in organizational procedures involves assuring accuracy 
and consistency, giving "voice" to those subject to the procedures (Folger 1977, Lind and van den Bos 2002), and providing explanations for managerial actions (Tyler and Lind 1992). Prior studies have shown that procedural fairness enhances job satisfaction and organizational commitment (Korsgaard et al. 1995), promotes acceptance of company policy and supervisor directives (Greenberg 1994), and facilitates organizational citizenship behavior (Tepper et al. 2001). Further, the fairness of decision-making procedures has been argued to affect the attitudes, behavior, and decision-making quality of organizational members (Kim and Mauborgne 1998, Korsgaard et al. 1995).

In this study, we advance the innovation literature by linking perceived procedural justice of top management's product decisions with project member collaboration and new product performance. Our key argument is that procedural justice in top management's product decisions is positively related to collaborative problem solving among project members who carry out product development activities, which is in turn related to new product performance. This argument is consistent with Kim and Mauborgne's (1998) suggestion that the exercise of procedural justice in decision-making contexts may have a positive effect on organizational performance via its beneficial impact on voluntary cooperation of organizational members.

However, we extend the literature in at least two ways. First, we posit and empirically test that collaborative problem solving plays a mediating role in the relationship between perceived procedural justice and new product performance. This not only highlights the importance of collaborative problem solving in new product development, but also helps us understand the process of how perceived procedural justice of top management decisions influences innovation. Second, we examine how environmental uncertainty and project members' perceived organizational commitment may moderate the relationship between perceived procedural justice in top management decisions and project members' collaborative problem solving. This contingency approach allows for a fine-grained understanding of the conditions under which executives' perceived procedural justice is related to the collaboration of project members in new product development. We thus respond to the recent notion of Lind and van den Bos (2002, p. 183) that, while justice researchers have tended to focus their work on showing that justice matters in organizations, they have not concerned themselves as much with why and how justice might play the role it does in organizational settings.

\section{Perceived Procedural Justice in Top Management Decisions Regarding New Product Development}

In the context of product innovation, we define perceived procedural justice in top management decisions as a project member's perceptions of the fairness of rules and processes used by top management to make decisions regarding the development of new products. ${ }^{1}$ Top management includes senior managers who are involved in the overall strategic direction of the firm and to whom project members report. These executives make critical decisions regarding new products to be developed by project members, such as (1) specifying the goal of developing the new product; (2) committing to new product development; (3) managing and allocating resources to the project; and (4) approving final policies in idea screening, product tests, and new product launch strategies.

Procedural justice researchers argue that organizational members are concerned about the fairness of the procedures that govern or affect them because procedural fairness signals a member's positive or valued position within the organization or group (Lind and Tyler 1988, Tyler and Lind 1992). Unfair treatment, in contrast, signals disregard and marginality. To the extent that organizational members believe they occupy a valued position within the organization, they may be more likely to fulfill their role requirements and improve their contribution to organizational performance. Extending this logic into the strategy area, researchers have argued that as management makes strategic decisions, organizational members who perceive these processes as fair are likely to cooperate in implementing the decisions and that this cooperative behavior will in turn lead to better performance (Kim and Mauborgne 1993, 1998).

Following this logic, we argue that as top management makes product innovation decisions in a procedurally just manner (e.g., considering project members' views and providing explanation for managerial actions), the market performance of a new product will improve. Successful new product market performance is often premised on the quality of the new product (Sethi 2000) and project members' ability to make quick and effective adaptations (Eisenhardt and Tabrizi 1995). It takes extensive time and resources to stabilize a product design and maintain balance between the product technology and the manufacturing process (Sethi 2000). Without such a balance, the quality of the product can be adversely affected (Clark and Fujimoto 1991). Moreover, faster product development and time to market lessen the potential for loss in profitability and the expenditure of resources on nonessential activities, changes, or mistakes (Clark and Fujimoto 1991). Product quality and time to market stem from the willingness of project members to contribute more than their organization may formally require of them (Cowherd and Levine 1992). Because project members' willingness to engage in such discretionary behaviors is largely a function of the procedures that govern them (Tepper and Taylor 2003), project members' perceptions of fairness can have a significant impact on the behaviors necessary for effective new product development. 
When top management decisions regarding product innovation are perceived as fair, project members will likely respond by increasing performance (e.g., Masterson et al. 2000). Indeed, prior research shows that the enactment of fair procedures is positively related to individual-level performance (e.g., Cohen-Charash and Spector 2001, Colquitt et al. 2001). However, when top management makes product decisions in a way that project members perceive as unfair (e.g., not giving opportunities for project members to challenge top management's opinions), conflict may arise that can sour project members' attitudes and affect their actions as they develop the new product and launch it in the market. Thus, perceived unfairness in top management decisions may jeopardize group processes and lead to reduced product quality, longer time to market, and hampered new product performance.

Hypothesis 1. Perceived procedural justice in top management decisions regarding new product development is positively related to new product market performance.

\section{Perceived Procedural Justice and New Product Performance: The Mediating Role of Collaborative Problem Solving Among Project Members}

Product innovation literature has paid increasing attention to the critical role of problem solving in new product development (McDonough and Barczak 1992, Thomke 1998, Thomke and Fujimoto 2000). The problem-solving process for new product development involves searching for new ideas and information, evaluating and selecting from alternative courses of action, designing and developing the new product, implementing the selected course of action, and launching the product. Product innovation necessitates effective problem solving because of the significant ambiguities and complexities extending from responses to internal (e.g., discovering a better technological solution) and external (e.g., a change in consumer needs or demands) changes (Thomke 1998). Because the ambiguity and complexity of the issues with which members must contend can overwhelm the capacities of any one member (Sheremata 2000), the success of the project often depends on the contribution and management of members' pooled resources and tacit information. As Hargadon and Sutton (1997) note, project members in product innovation often draw from their own past experiences and routines, both within and outside their current organization, to apply creative and specific technological solutions to complex problems.

Project members are expected to share knowledge through the implicit coordination of expertise as part of their formal project member job duties. Collective knowledge sharing enhances psychological safety
(Edmondson 1999) and fosters a climate of enriched team work and enhanced creativity (Scott and Bruce 1994). Yet knowledge can be shared merely to accomplish ongoing tasks, with little efficacy toward achieving project objectives - that is, the value of the information project members can use for new product performance depends on individual members' willingness to contribute tacit information and to work toward integrating that knowledge toward collective goals. Thus, beyond mere communication and exchange of information, each member must fully integrate idiosyncratic resources to create a synergistic effect greater than the sum of each member's individual assets.

The complexities inherent in new product development processes have prompted researchers to look closely at the interactions among project members as they strive to meet common goals (Brown and Eisenhardt 1995, Dougherty 1992, Song et al. 1997). Various concepts characterize problem-solving approaches to accomplishing specific tasks such as cooperation (Pinto et al. 1993), coordination (Argote 1982), interdependence (Stewart and Barrick 2000), integration (Kahn 1996), and collaboration (Liedtka 1996). Collaboration has surfaced more recently as a useful conceptualization for the project member interactions in evolving new product contexts (Jassawalla and Sashittal 1998, Liedtka 1996), particularly as other terms fail to adequately address the specialized challenges that confront project members in technological environments. Indeed, researchers have recognized the importance of collaboration as a projectlevel activity that contributes to both project and organizational effectiveness through the enhancement of the social, organizational, and psychological environment in which work is accomplished (Edmondson 1999).

In addition to a general sense of collective participation, collaboration among project members involves high levels of "at-stakeness," transparency, mindfulness, and synergies from their interactions (Jassawalla and Sashittal 1998). Applying these components to problem solving, project members attack problems rather than each other and resolve conflicts through honest and open discussion. This type of problem solving allows project members to build healthy relationships, challenge assumptions and perceptions, disclose information, understand potential predicaments, and make high-quality decisions. Further, collaborative problem solving can help overcome the physical and perceptual distance among project members from $R \& D$, marketing, and other functional groups, ensuring early involvement of all members and the sharing of responsibility. In product innovation contexts, collaborative problem-solving strategies reduce product development uncertainty and have been shown to result in significantly improved new product performance (Jassawalla and Sashittal 1998).

Although the importance of collaborative approaches to problem solving in practice is readily acknowledged, 
what is less understood is how to implement them. Integrating the view that procedures governing work practices affect individuals' reactions (Thibaut and Walker 1975), we adopt a procedural justice lens and suggest that fair process becomes an important means through which team members engage in collaborative efforts. Procedural justice research indicates that when employees perceive that decisions are made in a fair manner, they are more willing to obey team rules (e.g., Tyler 1997), provide resources to their team, and engage in extra-role behavior (or behaviors that contribute to the functioning of the organization but are not specified in job descriptions) (Tepper and Taylor 2003). Thus, in a new product development context, team members' willingness to engage in collaborative problem solving is likely manifested in procedurally fair situations. In contrast, procedurally unfair situations encourage unproductive, retaliatory behaviors that may decrease the effective functioning of a team and reduce members' efforts toward reaching collective goals (Colquitt et al. 2001).

Accordingly, we propose that when project members feel top management makes decisions regarding product innovation in a fair manner, project members are more likely to collaborate by sharing ideas in conceiving and executing new product development. However, when project members feel that the decision process is unfair, they may hoard ideas and refuse to collaborate. Further, project members who perceive a high level of procedural justice from top management are likely to become more interested and confident and to take greater ownership in the new product. Project members treated fairly in the new product development process will thus be more likely to solve problems or differences constructively (DiStefano and Maznevski 2000, Song et al. 1997) - thereby contributing to collaborative problemsolving efforts - than project members who are treated unfairly.

Our argument is consistent with research demonstrating that teams that collectively perceive higher levels of procedural justice engage in more helping behavior (Naumann and Bennett 2000). Similarly, other studies suggest that procedural justice enhances subsidiary cooperation with multinational headquarters' decisions (Kim and Mauborgne 1993). Thus, we propose that procedural justice by top management in new product decision making is positively related to project members' collaborative problem solving in new product development.

Hypothesis 2. Perceived procedural justice in top management decisions regarding new product development is positively related to project members' collaborative problem solving.

Above, we argue that perceived procedural justice in top management decisions is positively related to both new product performance and collaborative problem solving. We further posit that perceived procedural justice in top management decisions will benefit new product performance via its positive relationship with project members' collaboration. The rationale for our argument is based on Kim and Mauborgne's (1998) theoretical work. They propose that procedural justice fosters idea sharing and cooperation within teams and that this cooperation in turn leads to improved collective performance. Previous empirical work also supports the notion that such collaboration increases group performance. For example, MacCormack's (2001) study of Internet software development found that when members of a development team share their experience and knowledge, it can help the members analyze and respond during product development and allow greater efficiency in ongoing design activities. Further, in a meta-analysis of determinants of new product success, Montoya-Weiss and Calantone (1994) found that collaboration among project members is a critical factor affecting new product performance. Thus, consistent with Kim and Mauborgne's (1998) theoretical work and the above evidence that collaboration positively impacts performance, we posit that perceived procedural justice in top management decisions will benefit new product performance via its positive relationship with project members' collaboration.

Here, we predict a fully mediated relationship such that perceived procedural justice in top management decisions has a positive relationship with new product performance through the development of collaborative problem solving among project members. When collaborative problem solving has not been developed among project members, perceived procedural justice in top management decisions alone may not be related to new product market performance. Stated differently, perceived procedural justice in top management decisions may help shape the conditions for collaborative problem solving among project members, and it is collaborative problem solving that leads to superior product performance.

HYPOTHESIs 3. Collaborative problem solving mediates the relationship between perceived procedural justice in top management decisions regarding new product development and new product market performance.

\section{Perceived Procedural Justice and Collaborative Problem Solving: The Contingency View}

The key argument underlying the relationship between procedural justice and collaborative problem solving is that when project members perceive top management's decision making regarding new product development to be fair, they are more willing to engage in collaborative problem-solving efforts. However, this argument may 
not hold in all situations. Specifically, we propose that the relationship between procedural justice and collaborative problem solving is contingent on environmental uncertainty and project members' perceptions of their group's organizational commitment.

\section{Environmental Uncertainty}

Environmental uncertainty refers to the perceived rate of change and unpredictability of customers' product preferences and demands, and competitors' behavior responding to change (Miller 1988). Such uncertainty is particularly salient in new product development considering the high risk and time pressure involved (Atuahene-Gima and $\mathrm{Li}$ 2004, Brown and Eisenhardt 1995). In highly uncertain environments, project members encounter greater difficulty in collecting market information and devising new product plans. Also, rapid changes in the market environments increase the new product's risk of market failure.

We argue that the positive relationship between perceived procedural justice in top management decisions and collaborative problem solving among project members is stronger when environmental uncertainty is high than when it is low. Following the uncertainty management view (Lind and van den Bos 2002), fairness helps individuals manage uncertain environments by providing information about how to behave in such ambiguous situations. Specifically, fairness allows people to manage uncertainty because "it gives them confidence that they will ultimately receive good outcomes and because it makes the possibility of loss less anxiety-provoking or even, as in fair gambles, enjoyable" (Lind and van den Bos 2002, pp. 195-196). Because fair treatment signals that superiors will not exploit or exclude their subordinates, project team members may engage in collaborative problem solving as a way to reciprocate positive treatment from top managers.

However, unfair treatment coupled with high uncertainty creates a particularly threatening environment that engenders a high level of anxiety and leads employees to be less prone to exhibit attitudes and engage in actions that benefit their organization. Thus, procedural fairness plays a more important role in highly uncertain situations. Therefore, we propose that the positive relationship between procedural justice and collaborative problem solving will be stronger within uncertain environments. Previous literature indicates, for example, that the relationships between fairness and various outcomes such as affect (van den Bos 2001), trust in a superior (Long 2002), and support for organizational decisions (Lind et al. 2000) are stronger within highly uncertain environments.

HYPOTHESIS 4. When project members perceive a higher level of environmental uncertainty, the positive relationship between perceived procedural justice in top management decisions and collaborative problem solving among project members will be stronger.

\section{Project Members' Perceptions of Their Group's Organizational Commitment}

We propose that perceived organizational commitment of project members is another important moderating factor in the relationship between perceived procedural justice in top management decisions and collaborative problem solving. Organizational commitment refers to the extent to which project members feel themselves to be an important part of the organization and are willing to devote effort to the organization (Mowday et al. 1979). Project members' commitment to the organization results from a strong association with the attributes, values, or goals of the organization and suggests a level of attachment based on norms of respect and reciprocity that extend beyond self-interest (Eisenberger et al. 1990). Organizational commitment may help project members collaborate voluntarily. For example, Mayer and Schoorman (1992) find that employees who believe in and accept organizational values a more willing to exert considerable effort in benefit of the organization. Kim and Mauborgne (1998, p. 327) argue that "individuals with a high sense of felt commitment to an organization or decision identify with its goals and objectives and are likely to pursue them to the best of their abilities, in essence demonstrating a form of voluntary cooperation."

Rather than focusing on organizational commitment's main effect on collaboration, we argue that it acts as a moderator in the relationship between perceived procedural justice of top management decisions and collaborative problem solving among project members. In new product development, when project members perceive that their group has a high level of commitment to the firm, they anticipate and expect that the organization will treat them in a fair and respectful manner in return for their commitment to the firm (Brockner et al. 1992, p. 243). In this situation, perceived procedural justice in top management decisions becomes particularly important for project members, because it signals that members hold a valued position within the organization (Lind and Tyler 1988, Tyler and Lind 1992). Consequently, project members may be more willing to collaboratively solve product development problems and devote their efforts to product innovation. In contrast, when project members perceive a lower level of organizational commitment, perceived procedural justice of top management decisions regarding new product development becomes less important as expectations of fair treatment are reduced. Thus, procedural justice and organizational commitment will interact to have a positive relationship with collaborative problem solving such that when project members believe that their group has stronger organizational commitment, perceived procedural justice in top management decisions is more likely to be linked with higher levels of collaborative problem solving among project members. Evidence for this 
view stems from O'Reilly and Chatman (1986), who noted that individuals who believe they are treated fairly have stronger identification with their organizations and thus internalize the organizational goals promoted by top management. This prediction is also consistent with work by Brockner et al. (1992), which shows that individuals react more adversely to injustice when they are more committed to their institutions. Thus, the positive relationship between procedural justice and collaborative problem solving becomes stronger when perceived organizational commitment is higher.

HYPOTHESIS 5. When project members perceive that their group has greater organizational commitment, the positive relationship between perceived procedural justice in top management decisions and collaborative problem solving among project members will be stronger.

As a summary, Figure 1 depicts our hypothesized relationships among perceived procedural justice in top management decisions, collaborative problem solving among project members, and new product market performance.

\section{Method}

The study was conducted using firms compiled from the Dun \& Bradstreet Million Dollar database. One thousand manufacturing firms were randomly selected from several technology industries, including pharmaceutical products (SIC 2834), computer and office equipment (SIC 3572 and 3575), electronic components and accessories (SIC 3674 and 3675), and communication and telephone equipment (SIC 3663, 3669, 4812, and 4813). These industries were selected because firms in such industries are active in new product development and were among the most common sectors studied in prior innovation research (e.g., Autio et al. 2000, McGee et al. 1995).
A questionnaire was our major data-collection tool. To develop the questionnaire, we conducted personal interviews with CEOs and product managers and carefully examined the new product development and procedural justice literatures. To assess the face validity of the questionnaire items, we had three management scholars and two doctoral students serve as judges. After several iterations of item editing and refinement, we conducted pretest interviews with 12 managers who previously had participated in new product development projects. For example, the original measures of procedural justice we adapted from Kim and Mauborgne (1993) focused on decision makers' perception of their own decision-making process. In this study, we modified the measures by focusing on project members' perceptions of top management decisions. Top management includes those who actively participate in a firm's strategic decision making regarding product innovations (see Simons et al. 1999, p. 665). After the final revision, we administered the questionnaire to the full sample.

We collected data over a nine-month period in 2002. Along with the questionnaire, we sent a cover letter to a top manager (e.g., a CEO or president) from each firm, requesting him or her to identify a qualified manager from the firm to participate in the study. These key informants (e.g., new product, $\mathrm{R} \& \mathrm{D}$, or marketing managers) were members and leaders of new product development projects in their firms. They were asked to answer the survey questions based on their most recent product that had been in the market for a minimum of 12 months. We expected that these managers would have a clear recollection of projects in which they were most recently involved. Further, by asking them to focus on the most recent projects, we sought to minimize the social desirability bias in the selection of projects-that is, many respondents might otherwise choose to focus on their more successful projects. This method of data collection has been used in previous research on new product development (Moorman and Miner 1997, Sethi 2000).

Figure 1 Relationships Proposed and Tested in Theoretical Model

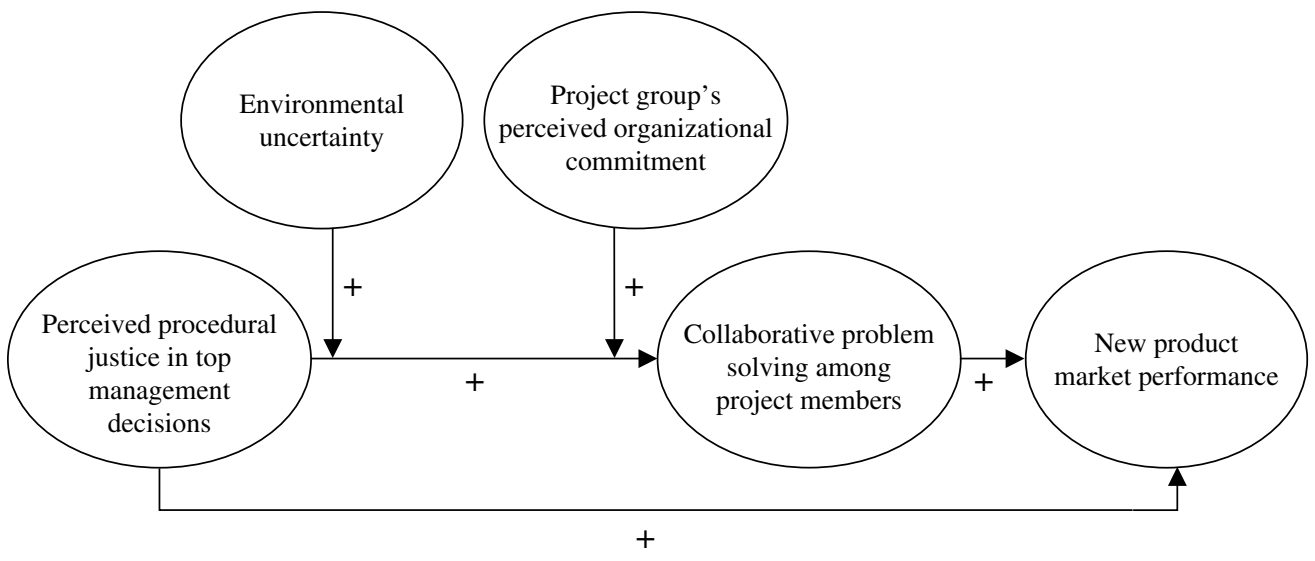


To enhance the effective response rate, we used several methods outlined by Westphal (1998). First, the survey packet contained a personalized cover letter that introduced the study, its potential value, and the importance of the executive's participation. Second, we offered participating respondents a copy of the survey results and research conclusions. We also included the name and telephone number of a contact person from whom they could receive a replacement survey if needed. We also assured participating executives of confidentiality. Third, three weeks following the first mailing, nonrespondents were telephoned, reminded of the questionnaire, and encouraged to complete and return it. Two weeks following these calls, we sent a second mailing to nonrespondents.

Of the 1,000 questionnaires we sent out, 76 were returned for reasons of address change or unwillingness to participate in the project. We received 121 questionnaires, but 12 were excluded from the analysis because of excessive missing values. Thus, the final sample size was 109 , representing a response rate of $11 \%$. Of the participating firms, $23.1 \%$ were in the pharmaceuticals industry, $23.1 \%$ were in electronic components and accessories industries, $29.6 \%$ were in computer and office equipment industries, and $24.1 \%$ were in communication and telephone equipment industries. Although somewhat low by general standards, our response rate of $11 \%$ is similar, and in some cases superior, to response rates in other research using questionnaires directed toward executives (e.g., Hambrick et al. 1993). As an example, Simons et al. (1999), in their attempt to survey executives, received only a $6 \%$ response rate. Indeed, previous research using the identical Dun \& Bradstreet database and mailing list has revealed similar datacollection difficulties with new companies involved in technology and product development (11\% response rate in this study) (McDougall et al. 1994). One possible explanation for the low response rate is that managers in technology industries who are making significant technological- and production-related advancements are reluctant or even unable to respond. For example, many managers in such industries are increasingly confronting quickly changing environments. Divulging insights about product development may be seen as an extreme liability. Also, in this post-Enron era, economic slowdown, corporate scandals, and other extraneous factors may have contributed to the low response rate.

Some would argue that such a low response rate would result in a sample selection bias. As Simons et al. (1999, p. 665) argued, however, in studies investigating complex relationships among measured variables, such as the current one, sample selection bias is unlikely to pose a threat. They note that "for selection bias to affect the validity of a moderated linear analysis, a sample idiosyncrasy would have to alter a moderated relationship to form a three-way interaction. Such an effect is improbable." Also, consistent with Eisenhardt and Tabrizi (1995), we argue that while sampling bias is always a possibility when there are nonrespondents, the potential for sampling bias was reduced by roughly equal response rates across industries in our sample.

To test whether our respondents were different from nonrespondents, we compared respondents' firm sizes and industry profiles with those of nonrespondents. We found no statistically significant differences, indicating that there was no systematic bias in our respondents in terms of industry or firm size. Additionally, we examined whether there were any differences in the means of the key constructs between the responses that were received before and those received after the reminders. The assumption of such an analysis is that later respondents are more similar to the general population than early respondents (Armstrong and Overton 1977). T-tests were performed to assess whether the means of the two groups were significantly different for each of the variables included in the model. No significant differences were found between groups.

Among the respondents, $44.2 \%$ were marketing managers, $33.6 \%$ were $\mathrm{R} \& \mathrm{D}$ managers, $10.6 \%$ were product development managers, and $11.6 \%$ were managers of other departments. Despite their different backgrounds (or functions), all were leaders of a product development project. Using ANOVA, we examined the differences in the study variables among these groups of respondents. No significant differences, save environmental uncertainty, were found among these groups of managers ( $F$ values for procedural justice, collaborative problem solving, organizational commitment, and new product market performance were $0.263,0.459,0.295$, and 2.517, respectively). Managers of other departments appeared to rate environmental uncertainty higher than marketing, $\mathrm{R} \& \mathrm{D}$, and product development managers. Also, to avoid the bias that only successful projects were selected, the respondents were asked to indicate the extent to which the new product they selected had achieved their objectives in terms of market share on a seven-point scale $(1=$ to a very little extent and $7=$ to a great extent). Nearly $37 \%$ of the respondents rated it as 4 or below. Therefore, the study sample is unlikely to be biased toward successful projects alone.

\section{Measures}

Except for new product market performance, which was measured based on a seven-point scale, all other multiitem constructs were measured on a five-point scale on which higher values were associated with higher levels of the construct. This approach may help provide a psychological frame hindering common method bias (Podsakoff et al. 2003). Specific measures for each construct are presented in Appendix 1.

New product market performance $(\alpha=0.85)$ was measured by five items that tapped the extent to which 
the new product had achieved important outcomes, including (1) sales relative to objectives, (2) return on sales relative to objectives, (3) profit margin relative to objectives, (4) return on investment relative to objectives, and (5) market share relative to objectives. To validate this measure, we solicited objective information from the key informants, because secondary archival sources for new product performance were unavailable in this study. This approach is commonly used in management literature (Autio et al. 2000). We asked the informants to report the sales growth rate for the new product to date (valid responses $=23$ ). Sales growth had a positive correlation with the perceptual market performance measure $(r=0.34, p<0.001)$, indicating some support for the validity of the perceptual measure.

We adapted Kim and Mauborgne's (1993) measure of procedural justice in multinationals' strategic decision-making processes as perceived by subsidiary top managers to serve as our measure of perceived procedural justice in top management decisions. This measure reflects how project members perceived the procedural justice of top management in new product decisions ( $\alpha=0.93$ ). Although Kim and Mauborgne's (1993) measure focused on the decisions of top management teams to invest in a subsidiary over time, we argue that our adaptation is valid in this context, given that top management's decisions about new products have important implications for project members' attitudes and behaviors and the development of new products. In our questionnaire, participants were asked to evaluate the manner in which top management (i.e., senior managers to whom the team reports) made decisions regarding the new product in question. Six items were used (see Appendix 1). These items receive fairly strong support in the existing literature (Lind and Tyler 1988) and relate well to Leventhal's (1980) criteria of procedural justice, such as consistency (i.e., procedures used to make decisions were applied consistently over time), correctability (i.e., mechanisms were in place to challenge management decisions), and representativeness (i.e., opinions of groups affected by decisions were consulted).

Perceived collaborative problem solving $(\alpha=0.87)$ represents the extent to which respondents perceived that project members solved problems collaboratively during new product development. A four-item scale was developed based on the work by Aram et al. (1971) and Dailey (1978). Perceived environmental uncertainty ( $\alpha=0.80$ ) was measured by four items that reflected the speed of change and unpredictability about customer demand and competitive conditions. These measures were adapted from Miller (1988). Perceived organizational commitment $(\alpha=0.82)$ was measured by four items adapted from Mowday et al. (1979). Respondents were asked to indicate the extent of their agreement with four statements that assessed their perceptions of their group's organizational commitment.
Control Variables. We also included several control variables to eliminate alternative explanations. Project team size was used as a control variable because prior research has noted that on average, larger teams are marked by less participation by individual members than smaller teams (Hare 1981). Project team size was measured by the number of people in the new product development project. Also, we controlled for duration of new product development, which was measured by the number of months required for project members to develop the new product. Firm size was calculated as the natural $\log$ of the number of employees in the firm. Product innovativeness $(\alpha=0.86)$ was measured by four perceptual items. These items considered how much the new product (1) was a breakthrough in the industry, (2) was radically different from existing products, (3) challenged existing technological ideas in the industry, and (4) was radically new to the firm. To control for industry effects, three industry dummies were created (pharmaceutical products, electronic components and accessories, and computer and office equipment) with the industry of communication and telephone equipment as the base group.

\section{Adequacy of the Measures: Reliability, Validity, and Common Method Variance}

We took several steps to ensure data validity and reliability. As noted earlier, we pretested the survey with 12 managers experienced in new product development. In the questionnaire itself, we used previously validated measurement items whenever possible to help ensure the validity of our measures. All of our multi-item scales had reliabilities (Cronbach's alpha) above the 0.70 threshold suggested by Nunnally (1978). To further check the validity of the informants' answers, we asked the respondents to indicate their involvement in the decisionmaking process for the new product and their amount of work experience in the firm. The mean for their involvement was 7.6 on a 10 -point scale (where $1=$ very less involved and $10=$ very highly involved). Average working experience was 8.2 years.

These numbers suggest that the selected respondents were experienced and knowledgeable about new product development in their firms, a result that increases our confidence in the quality and accuracy of our data. Also, as noted earlier, we motivated informants to provide valid data by assuring them of confidentiality and by offering a summary of the results. Most respondents $(101 / 109=93 \%)$ requested a summary of the results. This indicates that the informants were professionally interested in the study. Such interest likely improved the informant's conscientiousness and commitment to provide accurate data.

The use of a single data source for the study may raise concerns about the validity of the data. Although a number of studies have suggested that common method 
variance may not be as much of an artifact as is commonly assumed (e.g., Avolio et al. 1991, Spector 1987), Podsakoff et al. (2003, p. 900), based on a careful examination of the literature, suggest that common method variance is often a problem in behavioral research and researchers should implement measures to control for it. Specifically, we followed the Podsakoff et al. (2003) recommendation of integrating both procedural methods and statistical techniques for reducing the potential of common method variance. Regarding procedural remedies, we assured the respondents that their answers were confidential and that there were no right or wrong answers to the questions in the survey. Also as noted earlier, through pretest interviews with 12 managers, we carefully developed our questionnaires to avoid vague concepts and to keep questions simple and specific. These procedures likely reduce the respondents' 'evaluation apprehension and make them less likely to edit their responses to be more socially desirable, lenient, and acquiescent, and consistent with how they think the researcher wants them to respond" (Podsakoff et al. 2003, p. 888).

Regarding statistical techniques, we used Harman's one-factor test to check for the presence of common method variance (Podsakoff and Organ 1986). Significant common method variance would result in one general factor accounting for the majority of covariance in the variables. We subjected all the key variables to a factor analysis (the five key constructs listed in Appendix 1 plus product innovativeness). The analysis resulted in six factors with eigenvalues greater than one, with the first factor accounting for only $23 \%$ of total variance. This result suggests that common method variance is unlikely to have caused any significant relationships among variables in our study.

Further, we collected additional data by requesting that project managers who responded to our first questionnaire ask a knowledgeable informant with whom they had worked in the new product development process to complete a questionnaire. The questionnaire was identical to those completed by respondents from the original sample of 109 firms. Team members from 19 of the 109 original firms responded. This provided multiple respondent data for $17 \%$ of our sample. All the intraclass correlations of matched variables between the two informants were within the range of 0.89 and 0.96 (e.g., correlation for market performance between the two respondents was 0.92), indicating strong interrater reliability. In addition, we triangulated reported data with publicly available secondary data. We corroborated our data with data on firm size. The high level of correlation $(r=0.65)$ indicated the reliability of the selected variable and also reflected favorably on the likely accuracy of other reported data. Given the respectable scale intercorrelations and interrater reliability of the variables, we do not believe that common method variance presents a serious problem in our data.

We conducted a confirmatory factor analysis to assess the convergent and discriminant validity of the multiitem scales. The fit indices showed that the model fit the data reasonably well $\left(\chi^{2}=204.7, p<0.001\right.$; $\mathrm{GFI}=0.92 ; \mathrm{CFI}=0.91 ; \mathrm{RMSEA}=0.07)$. Each of the construct indictors loaded significantly on its intended factor, indicating convergent validity. To test for discriminant validity, we determined whether correlations between any two constructs (e.g., perceived procedural justice and organizational commitment) were significantly different from unity (Bagozzi and Phillips 1982). This required a comparison between two models: One model was constrained with the correlation equal to one, and the other was not. In each case, discriminant validity was evidenced by the statistically significant chi-square difference between the models. That is, a two-factor model had a better fit than a single-factor model, thus supporting the discriminant validity of the constructs.

Finally, we collected additional data from 91 project teams of students at the senior business undergraduate level ( $n=58$ teams) and the MBA level ( $n=33$ teams) at two large universities, one in the mountain west and the other in the southern United States. Student respondents were involved in a semester-long new product development project intended to replicate a product development team (the project involved team members comprised of different majors and functional backgrounds). The number of team members for each project varied from 2 to 7 , with an average of 4.8. The number of hours each project team spent developing the product varied from 30 to 250 , with an average of 61 hours. For this data collection, we used the same measures (or slightly modified) as with the sample of high-tech firms. However, we measured perceived procedural justice by using both the Kim and Mauborgne items and Colquitt's (2001) sevenitem measures of procedural justice $(\alpha=0.94)$. These two measures were highly correlated $(r=0.86)$, suggesting the validity of the scales used to measure the same construct. We followed the same procedure for testing the hypothesized relationships among the variables using the aggregated set of multiple-respondent data. Overall, the results for this team-based student sample were highly consistent with the results from the 109 hightech firms, providing support for the validity of our initial results and their generalizability to other contexts (results are available upon request). Given this confirmatory evidence, we focus the rest of the paper on our results from the survey of high-tech firms.

\section{Results}

Table 1 provides the descriptive statistics, zero-order correlations, and reliabilities for the variables. To test Hypotheses 1-3, we followed a standard procedure used 
Table 1 Correlation Matrix and Summary Statistics

\begin{tabular}{|c|c|c|c|c|c|c|c|c|c|c|c|c|c|}
\hline & Mean & S.D. & 1 & 2 & 3 & 4 & 5 & 6 & 7 & 8 & 9 & 10 & 11 \\
\hline $\begin{array}{l}\text { 1. New product market } \\
\text { performance }\end{array}$ & 4.47 & 1.41 & 0.85 & & & & & & & & & & \\
\hline 2. Perceived procedural justice & 3.94 & 0.82 & $0.27^{* *}$ & 0.93 & & & & & & & & & \\
\hline 3. Collaborative problem solving & 3.77 & 0.64 & $0.38^{* *}$ & $0.46^{* *}$ & 0.87 & & & & & & & & \\
\hline 4. Product innovativeness & 3.08 & 1.12 & 0.17 & $0.28^{* *}$ & 0.05 & 0.86 & & & & & & & \\
\hline 5. Environmental uncertainty & 3.14 & 0.86 & 0.09 & -0.11 & 0.00 & $0.21^{*}$ & 0.80 & & & & & & \\
\hline $\begin{array}{l}\text { 6. Perceived organizational } \\
\text { commitment }\end{array}$ & 3.83 & 0.53 & 0.14 & $0.22^{*}$ & $0.38^{* *}$ & -0.12 & $0.27^{* *}$ & 0.82 & & & & & \\
\hline 7. Project team size & 8.12 & 3.91 & $0.19^{*}$ & 0.00 & $0.24^{*}$ & 0.08 & -0.09 & -0.09 & - & & & & \\
\hline 8. Duration of decision making & 8.78 & 6.11 & -0.15 & -0.12 & 0.06 & -0.04 & -0.08 & $-0.23^{*}$ & $0.20^{*}$ & - & & & \\
\hline 9. Firm size & 215 & 632 & -0.14 & 0.04 & -0.01 & -0.07 & -0.01 & -0.02 & $0.23^{*}$ & 0.03 & - & & \\
\hline 10. Pharmaceutical products & 0.23 & 0.42 & 0.12 & 0.12 & -0.01 & -0.01 & -0.02 & -0.05 & 0.09 & 0.16 & 0.16 & - & \\
\hline $\begin{array}{l}\text { 11. Electronic components } \\
\text { and accessories }\end{array}$ & 0.23 & 0.42 & -0.15 & -0.02 & 0.03 & -0.07 & -0.06 & -0.06 & 0.08 & $0.31^{* *}$ & 0.09 & $-0.30^{* *}$ & - \\
\hline $\begin{array}{l}\text { 12. Computer and office } \\
\text { equipment }\end{array}$ & 0.29 & 0.46 & -0.10 & 0.01 & -0.09 & 0.04 & -0.10 & 0.08 & -0.12 & -0.16 & -0.01 & $-0.35^{* *}$ & $-0.35^{* *}$ \\
\hline
\end{tabular}

Notes. Numbers in diagonal are reliabilities. $N=109$.

${ }^{*} p<0.05 ;{ }^{* *} p<0.01$.

to test for mediating effects, "first, regressing the mediator on the independent variable; second, regressing the dependent variable on the independent variable; and third, regressing the dependent variable on both the independent variable and on the mediator" (Baron and Kenny 1986, p. 1177). A mediation effect calls for the following conditions: (1) the independent variable significantly predicts the mediating variable, (2) the independent variable significantly predicts the dependent variable without the mediator, and (3) the inclusion of the mediator attenuates the relationship between the independent and dependent variables while showing a significant relationship between the mediator and the dependent variable (Baron and Kenny 1986).

As shown in Table 2, we first regressed collaborative problem solving on procedural justice. Procedural justice demonstrated a significant positive relationship with collaborative problem solving $(b=0.33, p<0.001)$. This result showed support for Hypothesis 2-that is, perceived procedural justice in top management decisions regarding new product development was positively related to project members' collaborative problem solving. Then we regressed market performance on procedural justice. Procedural justice showed a significant positive relationship with market performance $(b=0.40$, $p<0.05$ ), thus supporting Hypothesis 1. Finally, we regressed market performance on both procedural justice and collaborative problem solving. When procedural justice and collaborative problem solving were entered simultaneously into the model, we found that collaborative problem solving was significantly related to market performance $(b=0.69, p<0.01)$ and procedural justice was no longer significantly related to market performance $(b=0.17$, n.s.). The results from these three steps met the criteria established by Baron and Kenny (1986) for full mediation. We thus found support for Hypothesis 3.
We used a hierarchical moderated regression analysis to test Hypotheses 4 and $5 .^{2}$ To reduce multicollinearity, we mean centered the independent and moderator variables before creating the interaction term (Aiken and West 1981). None of the variables in the study

Table 2 Regression Results: The Mediating Effect of Solving

\begin{tabular}{|c|c|c|c|}
\hline Variables & $\begin{array}{c}\text { Collaborative } \\
\text { problem } \\
\text { solving } \\
\text { Model } 1 \\
\end{array}$ & $\begin{array}{c}\text { Market } \\
\text { performance } \\
\text { Model } 2\end{array}$ & $\begin{array}{c}\text { Market } \\
\text { performance } \\
\text { Model } 3 \\
\end{array}$ \\
\hline Constant & $0.85^{\dagger}$ & 2.14 & 1.55 \\
\hline \multicolumn{4}{|l|}{ Control variables } \\
\hline Project team size & $0.04^{* *}$ & $0.10^{* *}$ & $0.07^{*}$ \\
\hline $\begin{array}{l}\text { Duration of new } \\
\text { product development }\end{array}$ & 0.02 & -0.03 & -0.04 \\
\hline Firm size & -0.01 & $-0.19^{*}$ & $-0.18^{*}$ \\
\hline Product innovativeness & -0.04 & 0.11 & 0.14 \\
\hline Pharmaceutical products & $-0.32^{*}$ & 0.12 & 0.34 \\
\hline $\begin{array}{l}\text { Electronic components } \\
\text { and accessories }\end{array}$ & -0.19 & -0.45 & -0.32 \\
\hline $\begin{array}{l}\text { Computer and office } \\
\text { equipment }\end{array}$ & -0.20 & -0.38 & -0.24 \\
\hline $\begin{array}{c}\text { Environmental } \\
\text { uncertainty }\end{array}$ & 0.02 & 0.12 & 0.11 \\
\hline $\begin{array}{l}\text { Perceived organizational } \\
\text { commitment }\end{array}$ & $0.35^{* *}$ & 0.23 & 0.10 \\
\hline \multicolumn{4}{|l|}{ Independent variables } \\
\hline $\begin{array}{l}\text { Perceived procedural } \\
\text { justice }\end{array}$ & $0.33^{* * *}$ & $0.40^{*}$ & 0.17 \\
\hline $\begin{array}{l}\text { Collaborative problem } \\
\text { solving }\end{array}$ & & & $0.69^{* *}$ \\
\hline$R$-square & 0.40 & 0.24 & 0.30 \\
\hline Adjusted $R$-square & 0.34 & 0.16 & 0.22 \\
\hline F-Value & $6.23^{* * *}$ & $3.01^{* *}$ & $3.59^{* * *}$ \\
\hline Change in $R$-square & & & $0.06^{* *}$ \\
\hline
\end{tabular}

Notes. Unstandardized regression coefficients are reported. $N=$ 109.

${ }^{\dagger} p<0.10 ;{ }^{*} p<0.05 ;{ }^{* *} p<0.01 ; * * * p<0.001$ 
Table 3 The Contingency Effect of Perceived Procedural Justice on Collaborative Problem Solving

\begin{tabular}{|c|c|c|c|c|}
\hline \multirow[b]{2}{*}{ Variables } & \multicolumn{4}{|c|}{ Collaborative problem solving } \\
\hline & Model a & Model b & Model c & Model d \\
\hline Constant & $0.85^{\dagger}$ & $1.26^{*}$ & $1.05^{*}$ & $1.54 * *$ \\
\hline \multicolumn{5}{|l|}{ Control variables and moderators } \\
\hline Project team size & $0.04^{* *}$ & $0.03^{*}$ & $0.05^{* * *}$ & $0.04^{* *}$ \\
\hline $\begin{array}{l}\text { Duration of new product } \\
\text { development }\end{array}$ & 0.02 & 0.03 & 0.02 & 0.02 \\
\hline Firm size & -0.01 & -0.01 & -0.00 & -0.01 \\
\hline Product innovativeness & -0.04 & -0.02 & -0.05 & -0.03 \\
\hline Pharmaceutical products & $-0.32^{*}$ & $-0.31^{*}$ & $-0.26^{\dagger}$ & $-0.24^{\dagger}$ \\
\hline $\begin{array}{l}\text { Electronic components and } \\
\text { accessories }\end{array}$ & -0.19 & -0.21 & -0.15 & -0.15 \\
\hline $\begin{array}{l}\text { Computer and office } \\
\text { equipment }\end{array}$ & -0.20 & -0.22 & -0.12 & -0.12 \\
\hline Environmental uncertainty & 0.02 & 0.09 & 0.01 & 0.11 \\
\hline $\begin{array}{l}\text { Perceived organizational } \\
\text { commitment }\end{array}$ & $0.35^{* *}$ & $0.42^{* * *}$ & $0.38^{* * *}$ & $0.46^{* * *}$ \\
\hline \multicolumn{5}{|l|}{ Independent variables } \\
\hline Perceived procedural justice & $0.33^{* * *}$ & $0.25^{* * *}$ & $0.27^{* * * *}$ & $0.16^{*}$ \\
\hline \multicolumn{5}{|l|}{ Interaction term } \\
\hline $\begin{array}{l}\text { Perceived procedural justice } \\
\quad \times \text { Environmental uncertainty }\end{array}$ & & $0.31^{* * *}$ & & $0.34^{* * *}$ \\
\hline $\begin{array}{l}\text { Perceived procedural justice } \\
\times \text { Perceived organizational } \\
\text { commitment }\end{array}$ & & & $-0.39 * *$ & $-0.46^{* * *}$ \\
\hline$R$-square & 0.40 & 0.46 & 0.44 & 0.51 \\
\hline Adjusted $R$-square & 0.34 & 0.40 & 0.38 & 0.45 \\
\hline$F$-value & $6.23^{* * *}$ & 7.16 & 6.73 & 8.22 \\
\hline Change in $R$-square ${ }^{a}$ & & $0.06^{* *}$ & $0.04^{* *}$ & $0.11^{* * *}$ \\
\hline
\end{tabular}

Notes. Unstandardized regression coefficients are reported. $N=$ 109.

${ }^{a}$ Change in $R$-square is relative to Model a.

${ }^{\dagger} p<0.10 ;{ }^{*} p<0.05 ;{ }^{* *} p<0.01 ;{ }^{* * *} p<0.001$

had a variance inflation factor above 2.0 , indicating the absence of multicollinearity problems. Also, as shown in Table 3, we entered the two interaction terms separately (see Models b and c). Then we entered both of them simultaneously (see Model d). We interpret our findings based on the results in Model d. Hypothesis 4 proposes that when environmental uncertainty is higher, the positive relationship between procedural justice and collaborative problem solving will be stronger. This hypothesis is supported $(b=0.34, p<0.001)$. To further explain this finding, we plotted the interaction effect in Figure 2. To create the figure, all variables in Model d in Table 3, except procedural justice and environmental uncertainty, were constrained to means. Procedural justice and environmental uncertainty took the values of one standard deviation below (i.e., low level) and above the mean (i.e., high level). Consistent with Hypothesis 4, Figure 2 shows that when project members perceive a high level of environmental uncertainty, procedural justice is positively related to collaborative problem solving. However, when project members perceive a low level of environmental uncertainty, this positive relationship is not present.

Hypothesis 5 proposes that when project members perceive that their group has greater organizational com-
Figure 2 The Moderating Effect of Environmental Uncertainty

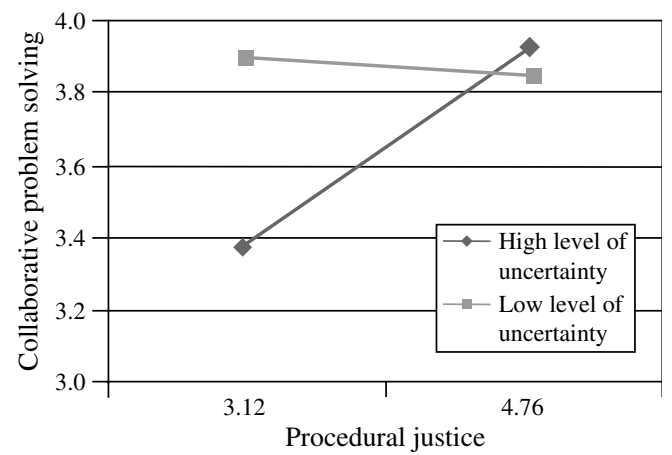

mitment, the positive relationship between procedural justice and collaborative problem solving will be stronger. The result is contradictory to our prediction ( $b=-0.46, p<0.001)$. To illustrate this finding, we plotted the interaction effect in Figure 3 by following the above procedures. Figure 3 indicates that when project members have a low level of organizational commitment, procedural justice is positively related to collaborative problem solving. However, when organizational commitment is high, procedural justice does not seem to have much of an effect on collaborative problem solving.

\section{Discussion and Conclusion}

In this study, we integrate the justice research in decision making (e.g., Kim and Mauborgne 1993) with the research on collaboration in new product development (Brown and Eisenhardt 1995, Song et al. 1997) by examining the relationship between perceived procedural justice in top management decisions and collaborative problem solving among project members in new product development. Results from new product development project team members in both high-tech firms and student-based project groups showed support for our

\section{Figure 3 The Moderating Effect of Organizational} Commitment

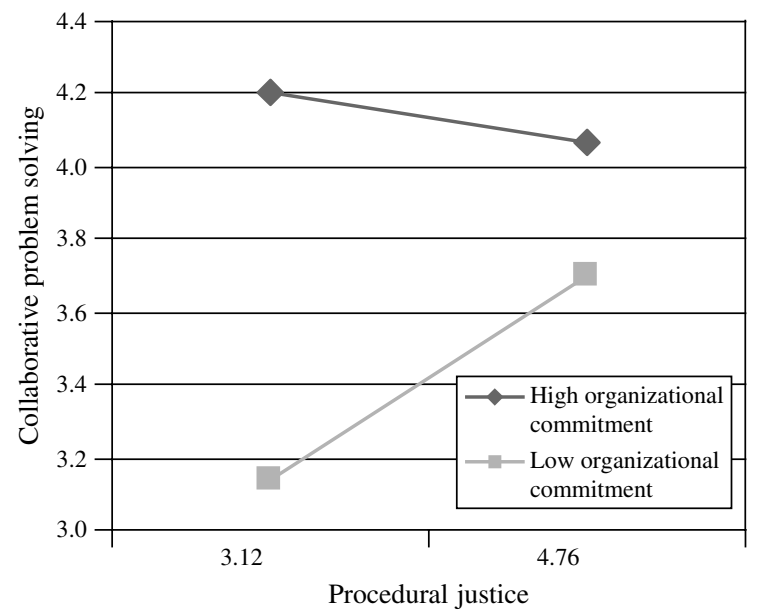


hypotheses. Specifically, perceived procedural justice in top management decisions is positively related to project members' collaborative problem solving in new product development, which in turn is positively related to new product performance. Our findings also demonstrate that the relationship between perceived procedural justice in top management decisions and collaborative problem solving among project members is contingent on environmental uncertainty and perceptions of the project group's organizational commitment.

An unexpected result in this study is the negative moderating effect of organizational commitment on the relationship between perceived procedural justice and collaborative problem solving. We hypothesized a positive moderating effect, expecting that when project members' organizational commitment is higher, perceived procedural justice in top management decisions tends to have a stronger positive relationship with collaboration among project members. However, the results suggest that the opposite may be the case. Our findings seem to imply that perceived procedural justice in top management decisions matters for project members' collaboration only when these members have a lower level of organizational commitment.

Although puzzling, a possible explanation for our results could be that organizational commitment acts as a substitute for procedural justice, such that employees who feel highly committed to the organization or perceive a high level of procedural justice may exhibit similar levels of collaborative problem solving. Conversely, when members lack both organizational commitment and a sense of procedural justice, they appear less likely to engage in collaborative attempts to solve problems. Our interpretation is consistent with previous findings. For instance, procedural justice has been found to be a possible substitute for situations in which employees receive negative outcomes (e.g., Brockner and Wiesenfeld 1996), such that employees will respond positively to organizational authorities as long as procedural justice is high when outcomes are low. Clearly, more research is needed to fully describe the role of project members' organizational commitment in the relationship between procedural justice by top management and collaborative problem solving among project members.

We believe this is the first empirical study to link procedural justice theory with new product development research. Contributing to research on product innovation, our results are noteworthy for two reasons. First, product innovation literature has documented the role of collaboration in new product development processes, and several studies have examined the factors affecting successful collaboration (Dougherty 1992, Jassawalla and Sashittal 1998, Song et al. 1997). In this study, we bring a procedural justice perspective into this line of research by examining the linkage between perceived procedural justice in top management decisions and collaborative problem solving among project members. Our results provide evidence that perceived procedural justice in top management decisions represents an important antecedent for collaborative problem solving among project members.

Second, although previous product innovation studies have highlighted the importance of top management support in terms of commitment and resource allocation (e.g., Zirger and Maidique 1990) in new product development, our results provide evidence that perceived fairness in top management decisions could be a force that pulls the project members together, thus improving new product performance. Further, our findings show that collaborative problem solving fully mediates the relationship between perceived procedural justice in top management product decisions and new product performance. These results suggest that when collaborative problem solving has not been developed among project members, perceived procedural justice in top management decisions, in and of itself, may not be related to new product market performance. Rather, it is collaborative problem solving that leads to superior product performance.

We believe that the introduction of procedural justice to the product innovation literature is an important step toward better understanding the role of top management in new product development. However, it is not our intention to cause readers to overweigh the contribution of procedural justice to new product development, relative to other factors. Although we focus on procedural justice as a determining factor in new product performance, as noted earlier, there are a number of other variables that can affect new product success. It seems likely that top management's exercise of procedural justice may affect its own commitment and resource allocation to new product development (Brown and Eisenhardt 1995, Swink 2000, Zirger and Maidique 1990), which subsequently impacts new product success. That is, top managers who disseminate fair procedures might also be likely to take greater ownership and demonstrate more commitment to the project. Further, top managers who make decisions in a procedurally fair manner may be more willing to advocate for necessary project resources than those who make decisions unfairly (Swink 2000). Yet one could be less concerned about these omitted variables because we included product innovativeness as a control variable in our model. By doing so, we controlled for the degree of task difficulty that affects both the resource and commitment contexts. Nonetheless, future research should provide more insights into the nature and extent of the contribution of procedural justice to new product success, relative to other factors.

Our findings have important implications for procedural justice research, particularly in the product innovation context. Our results show that the methods and 
procedures implemented by top management to make decisions regarding new product development are related to collaboration among project members, which in turn relates to new product performance. These findings provide evidence to support Kim and Mauborgne's (1998) proposition that procedural justice may relate to organizational members' performance via its positive effect on their voluntary cooperation. Moreover, we advance the literature by linking perceived procedural justice at the top management level with collaborative behavior at the project team level. Equally important, through a contingency perspective, we are able to identify how the relationship between procedural justice and collaborative problem solving is contingent on both environmental uncertainty and project members' perceived organizational commitment. Thus, our results provide a deeper understanding of how procedural justice becomes important in organizations in general and to product innovation in particular. As Lind and van den Bos (2002, p. 184) note, this kind of research will have important implications for the use of fairness-relevant actions in good management practice.

Our results highlight the importance of the application of procedural justice in managing ambiguities involved in new product development. Perceived procedural justice in top management decisions becomes more important for collaborative problem solving to occur in new product development in highly uncertain environments. These results support the argument of Lind and van den Bos (2002, p. 199) that, "When people are confronted with uncertainty in their environment, they turn to their impressions of fair or unfair treatment to help them decide how to react." Thus, top management should be mindful of the fairness of their decisions, particularly in uncertain situations.

Although this study is preliminary in nature, it provides some guidelines for managers to more effectively facilitate new product development. Our findings show that the application of procedural justice in new product development by top management may have a significantly positive relationship with new product performance via its positive association with project members' collaborative problem solving. Top management may help facilitate the collaboration among project members and the success of new product development by enacting fair methods and procedures. When project members feel that top management decisions regarding new product development are made in a fair manner, collaborative behavior is more likely to occur. As indicated in this study, such collaborative problem solving is critical for improving new product performance in the market.

\section{Limitations and Future Research Directions}

The contributions of this research should be viewed in light of several limitations. One limitation is that our data were cross-sectional, so no inferences of causality can be conclusively established; nor can we discount the possibility of reverse causality. For example, although we propose that procedural justice by top management may be related to collaborative problem solving, our study does not exclude the possibility that when project members are collaborative in problem solving, they are more likely to perceive fairness in the decision process. It is also possible that members of successful projects are more likely to report higher collaborative problem solving, commitment of the team, and procedural fairness. However, findings in the literature generally support the idea that procedural justice enhances organizational outcomes (e.g., Korsgaard et al. 1995, Masterson et al. 2000). Also, our moderated analyses of this relationship make simple reverse-causality arguments less tenable (Simons and Peterson 2000). Further, existing findings support the notion that collaborative problem solving is a critical factor affecting new product performance (e.g., MacCormack 2001, Montoya-Weiss and Calantone 1994). Nonetheless, a longitudinal design, cross-validation of the findings, and more data sources would enable us to further assess the causality of the hypothesized relationships.

Another limitation is that our data were collected via self-report questionnaires, giving rise to concerns about common method bias. As we noted earlier, our statistical analyses indicate no serious common method problems. Notwithstanding, we have implemented both procedural and statistical approaches to control common method bias. We reduced the potential for common method problems by employing previously validated measures (Spector 1987). We also attempted to validate our measure of new product performance with objective factors and a second team-based sample to help eliminate the concern of common method bias. Moreover, with regard to the supported interaction hypothesis, it is unlikely that respondents would have an "interaction-based theory" in their minds that could systematically bias their responses (Aiken and West 1981). In addition, results from our separate sample of 91 student project teams were highly consistent with the findings within the 109 high-tech firms, suggesting that results for the theoretical relationships proposed in this study can be replicated. This bolsters the argument for the external validity of the findings to a broader context of new product development. We acknowledge that the use of a single informant to assess team collaborative problem solving may be another limitation of the study. It is important for subsequent research to improve survey response rates, obtain team descriptions from more than one member, and include a measure of new product performance that is collected from data sources independent of a team member or members.

In this study, we focus specifically on perceived procedural justice in new product decisions by top management and find preliminary support for the idea that distal justice concerns (i.e., perceived procedural justice 
at top management) have a significant relationship with proximal outcomes (i.e., collaboration and new product performance). We acknowledge that there are other sources of fairness perceptions, such as procedural justice among project team members. Undoubtedly, justice perceptions among individual team members are significantly related to how collaboration occurs, is encouraged, or is hindered in new product development. Future research should explore how procedural justice perceptions among project members are related to organization-level outcomes. Other research might examine how perceptions of top management procedural justice may be linked with procedural justice at the project level and how consistency in justice perceptions may be related to similar outcomes, such as product innovativeness. Further, it would be important to understand the degree to which distal justice concerns (i.e., procedural justice perceptions about top management) matter in comparison to more proximal justice concerns (i.e., procedural justice perceptions of individual team members). Specifically, does the type of procedural justice stemming from one group have more influence on outcomes than another? Such analysis would greatly add to our understanding of how justice occurs on multiple levels. Further, our study has mainly drawn upon Kim and Mauborgne's conceptualization (1995, 1998) of justice related to procedures, yet justice can be multidimensional. Future research may enrich the current understanding of the role of fairness in new product development by including different dimensions of organizational justice (e.g., distributive, interpersonal, and informational justice) as suggested by Colquitt (2001).

Finally, our model was tested with data collected from technology industries. Future research should extend the findings of this paper and further our understanding of procedural justice in different industries (e.g., low-technology industries) and in different decisionmaking contexts. Exploring potential industry differences in our current findings may be a fruitful next step in understanding the factors that influence team processes. Accordingly, researchers should examine the salience of procedural justice and collaborative problem solving in contexts outside new product development and examine factors that may inhibit the application of fairness in new product decision making at the top management level. Strategy scholars interested in the effects of procedural justice on new product decision making also should consider other important moderators (e.g., organizational structure) that may interact with procedural justice in relation to organizational decision making.

\section{Acknowledgments}

The authors thank Kwaku Atuahene-Gima, Adrienne Colella, Angelo DeNisi, Jeff Dyer, Michael Hitt, Gerry Sanders, Dave Whetten, and Yan Zhang for their helpful comments on this paper. An earlier version of the paper appeared in the Best Paper Proceedings of the Academy of Management Annual Conference in Seattle (2003).

\section{Appendix 1. Measures for Multi-Item Constructs}

\section{Perceived Procedural Justice in Top Management Deci-} sions $(\alpha=0.93)$

Over the life of the new product project, when top management made decisions on issues concerning this new product, to what extent

a. were project members consulted and asked for their input?

b. were project members free to challenge management opinion?

c. were management decision making procedures fair over time?

d. was top management well informed and familiar with the project members' concerns?

e. did top management provide a full explanation for final decisions made?

f. did top management respect the project members' individual autonomy?

$(1=$ Not at all, $5=$ To a very great extent $)$

2. Collaborative Problem Solving Among Project Members $(\alpha=0.87)$

When conflicts arose among the project members during the new product development process,

a. we tried to exchange complete/accurate information to resolve them.

b. we played down the differences and emphasized common objectives.

c. we engaged in genuine collaborative effort to resolve them.

d. we discussed them focusing on the common goals of the strategy.

$(1=$ Strongly disagree, $5=$ Strongly agree $)$

3. New Product Market Performance $(\alpha=0.85)$

Please rate the extent to which the new product has achieved these outcomes to date:

a. Sales relative to objectives

b. Return on sales relative to objectives

c. Profit margin relative to objectives

d. Return on investment relative to objectives

e. Market share relative to objectives

$(1=$ To a very little extent, $7=$ To a great extent $)$

4. Perceived Environmental Uncertainty $(\alpha=0.80)$

Rate the degree to which you agree with the following statements that describe your principal industry over the last three years:

a. Customer preferences in our industry change quite rapidly.

b. Customer needs in our industry are changing fast.

c. Competitor activities in the market are quite uncertain.

d. The market competitive conditions are highly unpredictable.

$(1=$ Strongly disagree, $5=$ Strongly agree $)$

5. Perceived Organizational Commitment of the Project Group $(\alpha=0.85)$

Indicate the extent of your agreement with the following statements regarding your project group members:

a. Project members are willing to put a great deal of effort beyond that normally expected to help the new product development be successful. 
b. Project members talk up their work environment to their friends as a great place to work for.

c. Project members find that their values and the organization's values are very similar.

d. This organization really inspires the very best in them in the way of job performance.

$(1=$ Strongly disagree, $5=$ Strongly agree $)$

\section{Endnotes}

${ }^{1}$ Our focus here is on the role of top management in new product development. Thus, we exclusively focus on the fairness of the procedures used by top management in new product development. However, we acknowledge that other types of procedural justice (e.g., the perceived procedural justice at the project team level) are also important in affecting new product performance.

${ }^{2}$ Arguably, using structural equation modeling (SEM) may have allowed us to test our hypotheses in a more parsimonious fashion, especially given that the procedure allows for complete and simultaneous tests of all relationships. However, inherent in SEM's flexibility are complexity and ambiguity that can often be better explained using multiple regression techniques. Further, parameter estimates using SEM are based on covariances, which are generally unstable for small sample sizes. The parameters in our medium-size model would have warranted a sample size of at least 200 (Boomsma 1983), which was unavailable in the current study. Given these constraints, regression analysis was thus more appropriate for our data.

\section{References}

Aiken, L. S., S. G. West. 1981. Multiple Regression: Testing and Interpreting Interactions. Sage, Thousand Oaks, CA.

Ancona, D. G., D. F. Caldwell. 1992. Bridging the boundary: External activity and performance in organizational teams. Admin. Sci. Quart. 37 634-665.

Aram, J. D., C. P. Morgan, E. S. Esbeck. 1971. Relation of collaborative interpersonal relationships to individual satisfaction and organizational performance. Admin. Sci. Quart. 16 289-297.

Argote, L. 1982. Input uncertainty and organizational coordination in hospital emergency units. Admin. Sci. Quart. 27 420-434.

Armstrong, S. J., T. S. Overton. 1977. Estimating non-response bias in mail surveys. J. Marketing Res. 14 396-400.

Atuahene-Gima, K., H. Li. 2004. Strategic decision comprehensiveness and new product development outcomes in new technology ventures. Acad. Management J. 47 583-597.

Autio, E., H. J. Sapienza, J. G. Almeida. 2000. Effects of age at entry, knowledge intensity, and imitability on international growth. Acad. Management J. 43 909-924.

Avolio, B. J., F. J. Yammarino, B. M. Bass. 1991. Identifying common methods variance with data collected from a single source: An unresolved sticky issue. J. Management 17 571-587.

Bagozzi, R. P., L. W. Phillips. 1982. Representing and testing organizational theories: A holistic construal. Admin. Sci. Quart. 27 459-489.

Baron, R. M., D. A. Kenny. 1986. The moderator mediator variable distinction in social psychological research: Conceptual, strategic, and statistical considerations. J. Personality Soc. Psych. 51 $1173-1182$.
Boomsma, A. 1983. On the robustness of LISREL (maximum likelihood estimation) against small sample size and nonnormality. Unpublished doctoral dissertation, University of Groningen, The Netherlands.

Booz, Allen, and Hamilton. 1982. New Products Management for the 1980s. Booz, Allen, and Hamilton, Inc., New York.

Brockner, J., B. M. Wiesenfeld. 1996. An integrative framework for explaining reactions to decisions: Interactive effects of outcomes and procedures. Psych. Bull. 120 189-208.

Brockner, J., T. R. Tyler, R. Cooper-Schneider. 1992. The influence of prior commitment to an institution on reactions to perceived unfairness: The higher they are, the harder they fall. Admin. Sci. Quart. 37 241-261.

Brown, S. L., K. M. Eisenhardt. 1995. Product development: Past research, present findings, and future directions. Acad. Management Rev. 20 343-378.

Clark, K. B., T. Fujimoto. 1991. Product Development Performance. Harvard Business School Press, Boston, MA.

Cohen-Charash, Y., P. E. Spector. 2001. The role of justice in organizations: A meta-analysis. Organ. Behav. Human Decision Processes 86 278-321.

Colquitt, J. A. 2001. On the dimensionality of organizational justice: A construct validation of a measure. J. Appl. Psych. 86 386-400.

Colquitt, J. A., D. E. Conlon, M. J. Wesson, C. O. L. H. Porter, K. Y. Ng. 2001. Justice at the millennium: A meta-analytic review of 25 years of organizational justice research. J. Appl. Psych. 86 $425-445$.

Cowherd, D. M., D. I. Levine. 1992. Product quality and pay equity between lower-level employees and top management: An investigation of distributive justice theory. Admin. Sci. Quart. 37 302-320.

Dailey, R. C. 1978. The role of team and task characteristics in R\&D team collaborative problem solving and productivity. Management Sci. 24 1579-1587.

DiStefano, J. J., M. L. Maznevski. 2000. Creating value with diverse teams in global management. Organ. Dynam. 29 45-63.

Dougherty, D. 1992. A practice-centered model of organizational renewal through product innovation. Strategic Management $J$. 13 77-92.

Edmondson, A. 1999. Psychological safety and learning behavior in work teams. Admin. Sci. Quart. 44 350-383.

Eisenberger, R., P. Fasolo, V. Davis-LaMastro. 1990. Perceived organizational support and employee diligence, commitment, and innovation. J. Appl. Psych. 75 51-59.

Eisenhardt, K. M., B. N. Tabrizi. 1995. Accelerating adaptive processes: Product innovation in the global computer industry. Admin. Sci. Quart. 40 84-110.

Folger, R. 1977. Distributive and procedural justice: Combined impact of "voice" and improvement of experienced inequity. J. Personality Soc. Psych. 35 108-119.

Greenberg, J. 1994. Using socially fair treatment to promote acceptance of a work site smoking ban. J. Appl. Psych. 79 288-297.

Hambrick, D. C., M. A. Geletkanycz, J. W. Fredrickson. 1993. Top executive commitment to the status quo: Some tests of its determinants. Strategic Management J. 14 401-418.

Hare, A. P. 1981. Group size. Amer. Behavioral Scientist 24 695-708.

Hargadon, A., R. I. Sutton. 1997. Technology brokering and innovation in a product development firm. Admin. Sci. Quart. 42 716-749. 
Jassawalla, A. R., H. C. Sashittal. 1998. An examination of collaboration in high-technology new product development processes. J. Product Innovation Management 15 237-254.

Kahn, K. B. 1996. Interdepartmental integration-A definition with implications for product development performance. J. Product Innovation Management 13 137-151.

Kim, W. C., R. A. Mauborgne. 1993. Procedural justice, attitudes, and subsidiary top management compliance with multinationals' corporate strategic decisions. Acad. Management J. 36 502-526.

Kim, W. C., R. A. Mauborgne. 1995. A procedural justice model of strategic decision making: Strategy content implications in the multinational. Organ. Sci. 6 44-61.

Kim, W. C., R. A. Mauborgne. 1998. Procedural justice, strategic decision making, and the knowledge economy. Strategic Management J. 19 323-338.

Korsgaard, M. A., D. M. Schweiger, H. J. Sapienza. 1995. Building commitment, attachment, and trust in strategic decision-making teams: The role of procedural justice. Acad. Management J. 38 60-84.

Leventhal, G. S. 1980. What should be done with equity theory? New approaches to the study of fairness in social relationships. K. Gergen, M. Greenberg, R. Willis, eds. Social Exchange: Advances in Theory and Research. Plenium, New York, 27-55.

Liedtka, J. M. 1996. Collaborating across lines of business for competitive advantage. Acad. Management Executive 10 20-37.

Lind, E. A., T. R. Tyler. 1988. The Social Psychology of Procedural Justice. Plenum Press, New York.

Lind, E. A., K. van den Bos. 2002. When fairness works: Toward a general theory of uncertainty management. B. M. Staw, R. M. Kramer, eds. Research in Organizational Behavior. Elsevier, Boston, MA, 181-223.

Lind, E. A., J. Greenberg, K. S. Scott, T. D. Welchans. 2000. The winding road from employee to complainant: Situational and psychological determinants of wrongful termination claims. Admin. Sci. Quart. 45 557-590.

Long, C. 2002. Justice and outcomes. Unpublished doctoral dissertation, Duke University, Durham, NC.

MacCormack, A. 2001. Product development practices that work: How Internet companies build software. Sloan Management Rev. 42(2) 75-81.

Masterson, S. S., K. Lewis, B. M. Goldman, M. S. Taylor. 2000. Integrating justice and social exchange: The differing effects of fair procedures and treatment on work relationships. Acad. Management J. 43 738-748.

Mayer, R. C., F. D. Schoorman. 1992. Predicting participation and production outcomes through a two-dimensional model of organizational commitment. Acad. Management J. 35 671-684.

McDonough, E., III, G. Barczak. 1992. The effects of cognitive problem-solving orientation and technological familiarity on faster new product development. J. Product Innovation Management 9 44-52.

McDougall, P. P., J. G. Covin, R. B. Robinson, Jr., L. Herron. 1994. The effects of industry growth and strategic breadth on new venture performance and strategy content. Strategic Management J. 15 537-554.

McGee, J. E., M. J. Dowling, W. L. Megginson. 1995. Cooperative strategy and new venture performance: The role of business strategy and management experience. Strategic Management $J$. 16 565-580.
Miller, D. 1988. Relating Porter's business strategies to environment and structure: Analysis and performance implications. Acad. Management. J. 32 280-308.

Montoya-Weiss, M. M., R. Calantone. 1994. Determinants of new product performance-A review and meta-analysis. J. Product Innovation Management 11 397-417.

Moorman, C., A. S. Miner. 1997. The impact of organizational memory on new product performance and creativity. J. Marketing Res. 34 91-106.

Mowday, R. T., R. M. Steers, L. W. Porter. 1979. The measurement of organizational commitment. J. Vocational Behav. 14 224-247.

Naumann, S. E., N. Bennett. 2000. A case for procedural justice climate: Development and test of a multilevel model. Acad. Management J. 43 881-889.

Nunnally, J. 1978. Psychometric Theory. McGraw-Hill, New York.

O'Reilly, C., III, J. Chatman. 1986. Organizational commitment and psychological attachment: The effects of compliance, identification, and internalization on prosocial behavior. J. Appl. Psych. $71492-499$.

Pinto, M. B., J. K. Pinto, J. E. Prescott. 1993. Antecedents and consequences of project team cross-functional cooperation. Management Sci. 39 1281-1297.

Podsakoff, P. M., D. W. Organ. 1986. Self-reports in organizational research: Problems and prospects. J. Management 12 531-544.

Podsakoff, P. M., S .B. MacKenzie, J.-Y. Lee, N. P. Podsakoff. 2003. Common method biases in behavioral research: A critical review of the literature and recommended remedies. J. Appl. Psych. $\mathbf{8 8}$ 879-903.

Scott, S. G., R. A. Bruce. 1994. Determinants of innovative behavior-A path model of individual innovation in the workplace. Acad. Management J. 37 580-607.

Sethi, R. 2000. Superordinate identity in cross-functional product development teams: Its antecedents and effect on new product performance. J. Acad. Marketing Sci. 28 330-344.

Sheremata, W. A. 2000. Centrifugal and centripetal forces in radical new product development under time pressure. Acad. Management Rev. 25 389-408.

Simons, T. L., R. S. Peterson. 2000. Task conflict and relationship conflict in top management teams: The pivotal role of intragroup trust. J. Appl. Psych. 85 102-111.

Simons, T., L. H. Pelled, K. A. Smith. 1999. Making use of difference: Diversity, debate, and decision comprehensiveness in top management teams. Acad. Management J. 42 662-673.

Smith, K. G., C. J. Collins, K. D. Clark. 2005. Existing knowledge, knowledge creation capability, and the rate of new product introduction in high-technology firms. Acad. Management J. 48 346-357.

Song, X. M., M. M. Montoya-Weiss, J. B. Schmidt. 1997. Antecedents and consequences of cross-functional cooperation: A comparison of $\mathrm{R} \& \mathrm{D}$, manufacturing, and marketing perspectives. J. Product Innovation Management 14 35-47.

Spector, P. E. 1987. Method variance as an artifact in self-reported affect and perceptions at work: Myth or significant problem? J. Appl. Psych. 72 438-443.

Stewart, G. L., M. R. Barrick. 2000. Team structure and performance: Assessing the mediating role of intrateam process and the moderating role of task type. Acad. Management J. 43 135-148. 
Sutton, R. I., A. Hargadon. 1996. Brainstorming groups in context: Effectiveness in a product design firm. Admin. Sci. Quart. 41 $685-718$.

Swink, M. 2000. Technological innovativeness as a moderator of new product design integration and top management support. J. Product Innovation Management 17 208-220.

Tepper, B. H., D. Lockhart, J. Hoobler. 2001. Justice, citizenship, and role definition effects. J. Appl. Psych. 86 789-796.

Tepper, B. J., E. C. Taylor. 2003. Relationships among supervisors' and subordinates' procedural justice perceptions and organizational citizenship behaviors. Acad. Management J. 46 97-105.

Thibaut, J. W., L. Walker. 1975. Procedural Justice: A Psychological Analysis. Erlbaum Associates, Hillsdale, NJ.

Thomke, S. H. 1998. Managing experimentation in the design of new products. Management Sci. 44 743-762.
Thomke, S., T. Fujimoto. 2000. The effect of "front-loading" problem-solving on product development performance. J. Product Innovation Management 17 128-142.

Tyler, T. R. 1997. The psychology of legitimacy: A relational perspective on voluntary deference to authorities. Personality Soc. Psych. Rev. 1 323-345.

Tyler, T. R., E. A. Lind. 1992. A relational model of authority in groups. M. P. Zanna, ed. Advances in Experimental Psychology. Academic Press, San Diego, CA, 115-191.

Van den Bos, K. 2001. Reactions to perceived fairness: The impact of mortality salience and self-esteem on ratings of negative affect. Soc. Justice Res. 14 1-23.

Westphal, J. D. 1998. Board games-How CEOs adapt to increases in structural board independence from management. Admin. Sci. Quart. 43 511-537.

Zirger, B. J., M. A. Maidique. 1990. A model of new product development: An empirical test. Management Sci. 36867-883. 